\title{
Technical Vocabulary Instruction Between Language and Subject Practitioners: Who Does What?
}

\begin{abstract}
Abdullah Ali Alghamdi
Makkah College of Technology, Makkah, Saudi Arabia

This paper reports on the findings of a study which investigates the beliefs and practices of ESPTs (English for Specific Purposes Teachers) and CATs (Content Area Teachers) about collaboration when they teach ETV (English Technical Vocabulary) in a Saudi Arabian industrial college called YIC (Yanbu Industrial College). The central motive of this work is twofold: (1) The question of who should teach ETV items in an industrial domain, i.e., whether it is the job of ESPTs or CATs, or if it is the task of both parties; and (2) The issue of how ETV items should be taught, i.e., direct versus indirect VTSs (Vocabulary Teaching Strategies) and VDVs (Vocabulary Delivery Vehicles) that practitioners usually employ in order to achieve their goal(s). Methodologically, a triangulation of methods for six ESPTs and six CATs was utilized over almost a full semester at the college. The findings of this work indicate that though ESPTs and CATs view ETV teaching as reciprocal and value the collaboration between both parties, CATs believe they are more responsible for this task. It was also found that ETV teaching is more challenging to ESPTs than CATs. Finally, both parties were found overlapping in the VTSs and VDVs they employ to teach ETV items. The study concluded by providing some pedagogical implications which could serve more than one purpose by creating knowledge which will be useful for both parties.
\end{abstract}

Keywords: ESPTs (English for Specific Purposes Teachers), ETV (English Technical Vocabulary), CATs (Content Area Teachers)

\section{Introduction}

ETV (English Technical Vocabulary) definitions can be said to fall mainly into three categories: (1) classical; (2) frequency and range; and (3) a mixture of both definitions. Classical definitions regard ETV as one whose meaning is recognisably specific to a particular topic, discipline, or field of knowledge; thus, a certain level of knowledge of the field is required in order to understand it. The author terms them "classical definitions", because they are the most widespread in the literature. However, in some textual studies, where the occurrence of the technical word is primary, it was found preferable to define ETV according to its frequency and range (Becka, 1972, as cited in Sutarsyah, Nation, \& Kennedy, 1994). Frequency stands for the number of occurrences of certain ETV items in a text or corpus whereas range refers to the number of samples and texts in which certain ETV items occur. The third definition of ETV is a mixture of the two aforementioned definitions. Salager-Meyer 
(1985), for example, defined medical ETV items as: "Those high frequency, context-bound, or topic-dependent terms particular to a given medical specialty" (p. 6).

The topic of who should teach ETV has been widely debated among the specialists in the field. The outcome of these debates seems to identify three beliefs among researchers and teachers as to who should teach ETV items. One camp believes that teaching ETV is entirely the job of the CATs (Content Area Teachers) while the other believes that it is the job of the ESPTs (English for Specific Purposes Teachers) (Spack, 1988; Esteban \& Martos, 2002). More pragmatic camp's followers believe that it is the job of both parties with each party responsible for teaching ETV from a certain stance (Nation, 2001; Dudley-Evans \& St John, 1998; Tabtabaei, 2007).

Many researchers, lexicographers, and methodologists identify two approaches which can be used with both general and ETV items instruction. Direct vocabulary teaching, rich instruction, or "rich scripting" (McWilliam, 1998) goes beyond definitional information with the purpose of getting students actively involved with the word's meaning. The author also argues that this type of teaching usually leads to students learning words. Indirect vocabulary teaching, in turn, is the teaching or training of students on how and when to use some strategies so that they can independently use them in learning and increasing their lexical repertoire. Indirect vocabulary teaching has been given different labels across various vocabulary studies, such as, "strategy instruction", "learner-to-learn training”, and "learner training”.

This paper is interested in "teaching" in the sense of the delivery of material; the stages of presenting (i.e., teaching novel ETV items) and practising (i.e., reviewing already taught ones) will be the focus of this work. The impact of the other teaching aspects (e.g., the impact of tests, the impact of words selected and the impact of after-class vocabulary activities) will be addressed when additional explanations of their impact are needed about the stages of presenting and practising. It is also important to mention that the concepts involved in teaching vocabulary are not always operating in isolation nor calling for other teaching relations. Thus, teachers, students, textbook or course book, techniques, and tests are among the essential aspects that interlink to the term "teaching".

\section{Who Should Teach ETV Items?}

As mentioned earlier, teaching ETV items in any ESP field has been viewed the job of ESPTs, CATs, or both parties.

Considering ETV items instruction as the task of CATs promotes the specialized knowledge they are equipped with and valuing their roles as experts in the domain. In this regard, Byrd (1979) wrote: "It would smack of the widest sort of intellectual arrogance and ignorance to think that a specialist in ESL could brush up his physics and start leading his students through the physics texts and journals” (p. 15).

Different reasons have been provided for this view. Memory (1990), for example, argued that if CATs did not teach ETV some of these words would not be learnt by some students, which would consequently make the textbook increasingly difficult and prevent those students to understand and learn from it. Although this view carries lots of accuracy, it assumes that learning does not occur in any other ESP context except from teaching ETV items. ESP normally involves other tasks such as needs analysis, cooperation, collaboration, and team teaching ${ }^{1}$ between the main parties in the ESP context (i.e., ESPTs, CATs, and students). Spack (1988) claimed

\footnotetext{
${ }^{1}$ The concepts cooperation, collaboration, and team-teaching are addressed in the section about collaboration between both parties.
} 
that ESPTs are overloaded with student numbers in classes and struggle with their teaching loads, which makes it difficult for them to teach technical words which normally takes longer time to explain and requires more effort from the ESPT who sometimes lack the subject-matter knowledge. It can be, similarly, argued that CATs sometimes have similar responsibilities and may face the same obstacles. Other researchers (e.g., Jones, 1990; Koh \& Wong, 1990; Boyd, 1991) agreed with Byrd's point that ESPTs lack the proper content knowledge and should take care of the linguistic aspects instead. However, because it is difficult to separate language from content, Chamberlain (1980) and Hutchinson and Waters (1987) argued that ESPTs can help linguistically in the ESP context as we will discuss in the pragmatic view below.

The second camp views teaching ETV at an ESP context as the job of the ESPTs. This camp is quite small compared to the first one. Hyland (2002), for example, argued that the ESPT needs to understand subject-specialist topics and synthesise the information in order for it to be presented accurately. Other researchers (e.g., Kennedy, 1980; Koh, 1988) believed that language cannot be divorced from content and therefore that ESPTs need to teach ETV items. Fraser (2005) claimed that ESPTs need to: (1) know the different categories of lexis (i.e., types of ETV items) in a specialised context; therefore, knowing ETV generally alone is not enough, but instead that ESPTs need to know the different types of ETV such as fully technical, crypotechnical, and non-technical; (2) know the students' subject matter by investing a significant amount of time in acquiring subject knowledge; and (3) need to take advantage of the corpora in making their own specialised investigations.

The last camp is the largest of the three and the camp for which the author argues for its optimality since it views ESPTs, CATs, and students as partners in teaching ETV items. The proponents of this view (e.g., Chung \& Nation, 2003; Nation, 1990; Hutchinson \& Waters, 1987; Dudley-Evans \& St. John, 1998) view ETV teaching as a joint task of both ESPTs and CATs. According to Dudley-Evans and St. John (1998), the ESPT's job is to ensure that the students understand the ETV that appears as carrier content for an exercise, check if the students understand the language presented by the CATs, and cooperate with the students. They went on to argue that general vocabulary that has a high frequency in a specific field (i.e., high frequency ETV items) should be taught by the ESPTs, then by the CATs. Chung and Nation (2003) stressed that despite the limitations ESPTs face in teaching ETV, they should be prepared to help the students to: (1) gain the more general skills of recognising ETVs; (2) interpret definitions; (3) relate sense to core meaning; and (4) learn ETV word parts. Nation (1990) argued that ESPTs can help the learners with the vocabulary learning strategies with more concentration on two strategies namely: Word parts and guessing from context that help them learn the required ETV while the actual direct teaching remains the job of the CATs. This last argument has been widely accepted and the author of this paper believes that it clearly draws the separating line between the task of the ESPT and that of the CAT.

\section{How ETV Items Should Be Taught?}

The literature basically identified two types of vocabulary teaching approaches, i.e., direct and indirect vocabulary teaching which can be employed to all types of vocabulary and ETV items are no exception.

As direct vocabulary teaching goes, Graves (2009) argued that rich instruction should be supported by the five key principles from L2 teaching, which are: (1) Instruction of vocabulary builds on what the students already know, therefore using direct strategies like translations and cognates were successful in developing learners' 
vocabulary; (2) Instruction is personalized to learners' needs: one example can be used in student-friendly language; (3) Vocabulary instruction is taught in a meaningful context, e.g., guessing from the reading context; (4) Instruction of vocabulary is in-depth and comprehensive in the sense that it goes beyond surface-level definitions to cover a variety of vocabulary components, such as spelling-meaning connections and synonyms and antonyms; and (5) The learning process takes long time and the existence of the instruction, side-by-side, with it gives students the necessary academic support.

A large number of articles on how to teach vocabulary directly (e.g., Scott \& Nagy, 2004; Hiebert \& Kamil, 2005; Baumann \& Kameénui, 2004; Nation, 2001) has been written. Mezynski (1983) and Stahl and Fairbank (1986), for instance, are two studies that reviewed direct instruction of vocabulary and concluded that in order for it to be effective it first needs to offer multiple exposures of the words being taught: This is usually achieved by using recycling and repetition strategies. Secondly, it should involve breadth of information: this usually occurs when definitions are used jointly with other VTSs (Vocabulary Teaching Strategies), like text guessing, exemplifications and the like. Finally, it should also involve depth; depth of direct vocabulary instruction can be noticed when the student thinks and interacts with the word. Having both depth and breadth present in rich instruction of vocabulary will usually "establish networks of connections from the new words being learned to words, experiences, and ideas they already have” (McKeown \& Beck, 2004, p. 16).

The type of vocabulary that should be taught directly is of great importance in direct vocabulary teaching. The notion of "tiers" is quite relevant to our discussion here. In Table 1, Nation (1990, 2001) stressed that a certain amount of time should be spent on teaching high-frequency words until the students have learnt them. He argued that academic vocabulary should be taught if the student is in upper high school or in tertiary education. He also advised that technical vocabulary should be taught directly by the subject teacher instead of the ESPT. According to him, ESPT can help mainly in the vocabulary learning strategies. By contrast, he cautioned against teaching low-frequency vocabulary.

Table 1

Types of Vocabulary, Their Features, and Implications for Teaching

\begin{tabular}{|l|l|l|l|}
\hline Type of vocabulary & Number of words & Frequency & Implications for teaching and learning \\
\hline High-frequency words & 2,000 & $\begin{array}{l}\text { Occur frequently in all } \\
\text { kinds of texts }\end{array}$ & $\begin{array}{l}\text { Spend a lot of time on these words. Make } \\
\text { sure they are learnt }\end{array}$ \\
\hline Academic-vocabulary & 800 & $\begin{array}{l}\text { Occur frequently in most } \\
\text { kinds of texts }\end{array}$ & $\begin{array}{l}\text { If students are in upper secondary school or } \\
\text { in tertiary education, spend a lot of time on } \\
\text { these words. Make sure they are learnt }\end{array}$ \\
\hline Technical vocabulary & $\begin{array}{l}\text { About 1,000 to 2,000 for } \\
\text { each subject }\end{array}$ & $\begin{array}{l}\text { Sometimes occur } \\
\text { frequently, in specialized } \\
\text { texts }\end{array}$ & $\begin{array}{l}\text { Learning the subject involves learning the } \\
\text { vocabulary. Subject teachers can deal with } \\
\text { the vocabulary, but the English teacher can } \\
\text { help with learning strategies }\end{array}$ \\
\hline Low-frequency vocabulary & About 123,000 & $\begin{array}{l}\text { Do not occur very } \\
\text { frequently }\end{array}$ & $\begin{array}{l}\text { Teach strategies for dealing with these } \\
\text { words. The words themselves do not } \\
\text { deserve teaching time }\end{array}$ \\
\hline
\end{tabular}

Note. Source: Nation (1990).

On the other hand, indirect vocabulary teaching which revolves around training the students on using certain vocabulary learning strategies to learn ETV items independently has been also highlighted in the literature. Rivers (1983) argued that language teachers can help students by giving them ideas on how to learn these words effectively. Gardner and MacIntyre (1992) believed that learning strategies are the milestones in language 
learning since they help students retrieve and store material as well as facilitating learning by structuring its environment. With all these benefits sketched out, the good teacher is the one who teaches his/her students "how to learn, how to remember, how to think, and how to motivate themselves” (Weinsten \& Mayer, 1986, p. 315). Rasekh and Ranjbari (2003) argued that strategy instruction improves both the learning product (i.e., what to learn) and the process (i.e., how to learn). This happens, according to them, because vocabulary instruction enhances the students' awareness of how to learn effectively as well as motivating them.

How the teacher indirectly (i.e., by teaching vocabulary learning strategies) teaches vocabulary is another vital topic in the ESP context. Indirect vocabulary teaching occurs when the teacher creates opportunities for such learning. This means that the teacher can encourage certain vocabulary activities, like bringing additional reading texts and training the students on using the strategy of guessing the meaning from the context. Outside the classroom, the teacher may ask the student to surf the Internet or go to their institution's library to look for particular technical words of Greek or Latin origin after training them on the word part strategy. Duke and Pearson (2002) identified five stages for teaching vocabulary indirectly and for transferring the strategy from the teacher to the students, as follows: (1) the teacher provides an explicit description of the strategy-when and how it should be used; (2) the teacher and/or student model the strategy in action; (3) collaborative use of strategy in action should follow; (4) students' use of strategy with gradual release under the guidance of the teacher; and (5) students' independent use of strategy.

\section{VTSs and VDVs (Vocabulary Delivery Vehicles) for ETV Items Instruction}

One of the important issues in teaching both general and ETV items is which VTSs and/or VDVs should be used in a task that is vocabulary focuses (i.e., intentional vocabulary teaching), or a task which is not vocabulary focused (i.e., incidental vocabulary teaching). However, deciding on which VTSs and/or VDVs should be used by ESPTs and CATs is another form of the needed collaboration when teaching ETV items.

Though a plethora of articles has been written about vocabulary learning strategies, little empirically-oriented studies have been carried out about VTSs. Consequently, no specialized taxonomy has been developed about VTSs and all available about them is no more than honest advice from experienced researchers and teachers (Özturk, 2006).

For the sake of simplicity in this article, the author will divide VTSs into vocabulary for presentation and vocabulary for practice. The former are those concerned with introducing novel ETV items (e.g., definitions, exemplifications, and real objects) while the latter are about the already taught words (e.g., semantic mapping, synonyms and antonyms, and memory images). The presentation and practice VTSs can be used directly or indirectly, intentionally or incidentally, as we demonstrated earlier in this section, and may target different aspects of the lexical information of the ETV items. For example, if an ESP and/or CAT defined an ETV item for the first time in a task that is not vocabulary focused to show the meaning to his students, we can say that definition has been used incidentally and directly for meaning presentation. Equally, when word parts technique is used by a teacher to show the different parts of an ETV items in a task that is vocabulary focused and in a revision class, we can bet safe that word parts has been used intentionally and directly for form practice.

On the other hand, we need to know that VTSs do not work in isolation of one another. Therefore, two or more techniques might couple up to help the teacher explain particular information about a certain idea. They, 
similarly, could substitute one another. Thus, a teacher in a certain circumstances might prefer translations over definitions or semantic mapping over synonyms and antonyms.

VDVs are not strategies in themselves but rather medium for transferring them. Therefore, VDVs such as, audio-visual aids, flash cards, and wall charts can all support the use of the main VTSs.

\section{Collaboration Between ESPTs and CATs on the Issue of "Who" and "How"}

This section looks closely at the pragmatic camp's views about how collaboration should be exploited between ESPTs and CATs.

Dudley-Evans and St. John (1998) argued that CATs and ESPTs can play the role of the collaborators through three stages, which are cooperation, collaboration, and team-teaching. The cooperation stage, according to them, stands for the simple phase where the ESPT takes the initiative and enquires into the students' subject areas as well as into the tasks defining their target situation. Collaboration implies the mutual interest on the part of both parties for the sake of the students. Collaboration usually takes different formats, as: (1) CAT provides the topic, i.e., "real content" to introduce the linguistic side-the "carrier content"; (2) ESPTs prepare students linguistically to have the necessary competence in academic situations; and (3) CATs guide ESPTs in selecting the topic relevant to the subject-matter. Team-teaching is the last resort where both types of teacher work jointly and each party focuses on his/her area.

Chamberlain (1980) stressed that collaboration between the ESPTs and CATs should not be simplified as merely collaboration between one ESPT type with one CAT type. Rather, he argues that it involves: (1) collaboration between recruited ESPTs themselves; (2) collaboration between local ESPTs themselves; (3) collaboration between ESPTs and recruited CATs; and (4) collaboration between both recruited and local ESPTS and CATs. However, this division seems to concentrate on collaboration from two different areas, which are the nativeness and type of the teacher. The issue of nativity can, in the author's opinion, be criticized by saying that not all recruited teachers are native speakers.

Neither should collaboration be seen as always being a problem-free task. Widdowson (1978) believed that team-teaching is costly in terms of time and is more situated at the secondary level than at the tertiary level. Moreover, the author of this paper thinks that collaboration needs each party to eliminate from themselves the authoritative spirit, to be prepared and ready to collaborate whenever and wherever needed. Each party also needs to know precisely what is needed from him/her when a classroom-based collaboration is in action, which is usually an inconvenient task for some teachers, and YIC (Yanbu Industrial College) is no exception in this matter.

\section{Method}

Because triangulating methods reduce observer and interviewer bias and enhance the validity and reliability of the information (Johnson, 1992). The author used the pre-observation semi-structured interview to investigate the practitioners' beliefs on several issues, i.e., beliefs on ETV teaching strategies and techniques, the roles of ESPTs and CATs and the impact of other wider issues on the act of teaching technical vocabulary. Observation in this study examines the actual practices of teachers in their classrooms. The post-observation interview, i.e., stimulated recall connects the beliefs to the practices and seeks out further interpretations from the participants 
The target population of this study was the ESPTs (totaling roughly 60 male ESPTs with only six selected for participation) and the CATs (totaling roughly 120 male CATs with only six selected for participation) at YIC. Table 2 displays and summarizes the participants' profiles. The participants specialized mainly in four different disciplines which are electronics, electricity, mechanics, and management with different teaching experiences.

Table 2

A Participants' Background Information

\begin{tabular}{|c|c|c|c|c|c|c|}
\hline Participant & Type & Degree held & $\begin{array}{l}\text { Teaching experience } \\
\text { (years) }\end{array}$ & Major & Nationality & Module observed at YIC \\
\hline ESP NS & ESPT & BA TEFL & 12 & TEFL & Jordanian & 001 Technical English \\
\hline ESP NL & ESPT & MSc. in ESP & 18 & ESP & Jordanian & Business English 012 \\
\hline ESP JB & ESPT & $\begin{array}{l}\text { BA in Education \& } \\
\text { TESOL Certificate }\end{array}$ & 19 & TESOL & American & 001 Technical English \\
\hline ESP PM & ESPT & BA in Social Sciences & 27 & Social Sciences & British & 002 Technical English \\
\hline ESP WH & ESPT & BA in Linguistics & 7 & Linguistics & Saudi & Business English 011 \\
\hline ESP MD & ESPT & $\begin{array}{l}\text { MA in language \& } \\
\text { Literature }\end{array}$ & 8 & $\begin{array}{l}\text { Language \& } \\
\text { Literature }\end{array}$ & American & 001 Technical English \\
\hline CAT ZU & $\begin{array}{l}\text { CAT } \\
\text { Elect. }\end{array}$ & BA in Electronics & 21 & Electronics & Indian & $\begin{array}{l}\text { Electronic } \\
\text { Troubleshooting \& } \\
\text { Maintenance }\end{array}$ \\
\hline CAT AN & $\begin{array}{l}\text { CAT } \\
\text { Elect. }\end{array}$ & BA in Electrical Power & 18 & Electrical Power & Indian & Electrical Troubleshooting \\
\hline CAT MZ & $\begin{array}{l}\text { CAT } \\
\text { Mech. }\end{array}$ & $\begin{array}{l}\text { MA in Mechanical } \\
\text { Engineering }\end{array}$ & 18 & Manufacturing & Indian & Machine Process (II) \\
\hline CAT AL & $\begin{array}{l}\text { CAT } \\
\text { Econ. }\end{array}$ & MA in Finance & 3.5 & Economics & Pakistani & Introduction to Economics \\
\hline CAT VN & $\begin{array}{l}\text { CAT } \\
\text { Mang. }\end{array}$ & Ph.D. in Mang. & 10 & $\begin{array}{l}\text { General } \\
\text { Management }\end{array}$ & Philipino & Industrial Supervision \\
\hline CAT KU & $\begin{array}{l}\text { CAT } \\
\text { Mech. }\end{array}$ & $\begin{array}{l}\text { MA in Mechanical } \\
\text { Engineering }\end{array}$ & 12 & $\begin{array}{l}\text { Mechanical } \\
\text { Engineering }\end{array}$ & Indian & Equipment Maintenance \\
\hline
\end{tabular}

\section{Data Collection}

\section{Pre-observation Semi-structured Interviews}

This instrument was employed prior to the classroom observations to essentially examine the participants' beliefs from different corners. Among the other objectives of the pre-interviews are: To obtain the initial general background information for both ESPTs and CATs, to check the extent to which ESPTs and CATs view teaching technical vocabulary as a problem, to investigate the information on the wider (non-linguistic) issues that influence both parties' beliefs about collaboration and, therefore, inform their practices.

The pre-interview questions were divided mainly into three parts. Part two of this instrument was the essence of this work since it included actual beliefs regarding teaching ETV items by ESPTs and CATs. Therefore, issues of teachers' beliefs on who should teach EVT items and ESPTs' and CATs' beliefs on how ETV items should be taught were all addressed. To this end, the two main questions were asked: (1) In your opinion, who should teach ETV: ESPTs and/or CATs, i.e., subject specialists?; and (2) Why should ETV be taught by those you mentioned?

The two main questions were then followed by other questions from pre-designed prompt cards to find out more about the participants' beliefs. For example, the following questions were asked about the form of the ETV 
items: (1) Who do you think should teach how the ETV items should be pronounced?; and (2) Who do you think should show the different word parts available in the ETV items?.

\section{Semi-structured Observations}

The observation sheet was designed to contain both a checklist and space for free field notes to check the participants' practices. As far as the researcher role was considered, the author decided to be a non-participant observer. Every participant was almost observed three times. The researcher was basically observing the ESPTs and CATs with the intention of comparing their actual practices with their previously stated beliefs. However, his presence, as a non-participant outsider (i.e., not a member of staff in the college or broadly within the RCYIC ${ }^{2}$ ) with no evaluative purposes, made the participants feel more comfortable and reduced the risk of "observers" paradox' ${ }^{3}$. This can normally lead to observing more natural behaviors. All the lessons were fully audio-recorded. Recordings were used for more careful revision afterwards. Each recording took approximately 50 minutes for one lecture or approximately 90 minutes if there were two lectures combined. No breaks took place between lectures.

\section{Post-observation Semi-structure E-mailing Interviews (Stimulated Recall)}

After having a cursory look over the participants' pre-observation interviews and observation records, the researcher immediately post-interviewed the participants in order to compare their beliefs with their practices. The researcher was forced to email the stimulated recall interviews to the participants because they were fully occupied with certain office work in preparation for the ABET (Accreditation Board for Energy and Technology assessment). They were specifically awaiting an overseas team who was coming from the U.S. for this purpose and they did not have time for long post-interviews in the college. Moreover, the time given to the data collection by the study sponsor was quite limited. The participants and the author agreed to have email post-interviewing asynchronously (i.e., the author would email them the interview questions and audio files, and would await their replies later at an agreed time rather than immediate chat-like responses).

\section{The Findings}

The following section addresses teachers' beliefs about whose task is to teach ETV items and how this job should be done, which is a central theme in the present study. Figure 1 displays the topics and subtopics about which teachers have beliefs when teaching ETV items, which are basically the themes that emerged from the analysis of the data.
(1) Teachers' beliefs on how ETV items should be taught:
(a) Practitioners' beliefs about the VTS \& VDV that should be used.
(b) ESPTs' and CATs' beliefs about why some VTS \& VDV should be used more than others.
(2) Teachers' beliefs on who should teach ETV items:
(a) Practitioners' overall beliefs on who should teach ETV items.
(b) Practitioners' beliefs about why some ETV items should be taught by ESPTs, CATs or both parties.

Figure 1. Topics that teachers have beliefs about when teaching ETV items.

\section{Teachers' Beliefs on How ETV Items Should Be Taught}

This study chose to distinguish four levels of frequency of beliefs regarding the type of VTS and VDV that

\footnotetext{
2 RCYIC stands for the Royal Commission of Yanbu Industrial City.

${ }^{3}$ Observer's paradox refers to the phenomena where the presence of the observer influences the observation of an event.
} 
participants believe should be used in teaching ETV items. Level one consists of the VTS and VDV that all of the teachers reported they should use in teaching ETV items. Level two is about the strategies that "most" teachers used (i.e., strategies that more than half of the teachers of the same group reported they should use). Level three contains the VTS and VDV which were believed to be used by "a few" teachers (i.e., half or less of the teachers of the same group reported that they should use). Finally, level four consists of the VTS and VDV that "none" of the teachers reported they should use in teaching ETV items. Table 3 shows these four levels for ESPTs and identifies the strategies associated with each of them.

Table 3

Levels of Frequency of ESPTs'Beliefs About Types of VTS and VDV That Should Be Used

\begin{tabular}{|c|c|c|}
\hline Level of frequency & Nature of the level & Strategies of the level \\
\hline Level one & $\begin{array}{l}\text { VTS and VDV that all ESPTs believe should } \\
\text { be used }\end{array}$ & $\begin{array}{l}\text { Body actions, definitions, exemplifications, dictionary use, } \\
\text { repetition, guessing from context, vocabulary tests, recycling }\end{array}$ \\
\hline Level two & $\begin{array}{l}\text { VTS and VDV that most (4-5) ESPTs } \\
\text { believe should be used }\end{array}$ & $\begin{array}{l}\text { Pictures } \\
\text { Translations } \\
\text { Synonyms and antonyms } \\
\text { Games } \\
\text { Semantic mapping } \\
\text { Collocations } \\
\text { Attention to register } \\
\text { Conversation and dialogue } \\
\text { Word parts }\end{array}$ \\
\hline Level three & $\begin{array}{l}\text { VTS and VDV that a few (1-3) ESPTs } \\
\text { believe should be used }\end{array}$ & \begin{tabular}{|l|} 
Real objects \\
Scales \\
Technology aids \\
Posters and illustrations \\
Memory images \\
Flash cards \\
\end{tabular} \\
\hline Level four & $\begin{array}{l}\text { VTS and VDV that no ESPTs believe should } \\
\text { be used }\end{array}$ & Labelling \\
\hline
\end{tabular}

Likewise, the CATs have the same four levels of belief (see Table 4), but with different VTS and VDV.

Table 4

Levels of Frequency of CATs' Beliefs About Types of VTS and VDV That Should Be Used

\begin{tabular}{|l|l|l|}
\hline Level of frequency & Nature of the level & Strategies of the level \\
\hline Level one & $\begin{array}{l}\text { VTS and VDV that all CATs believe should } \\
\text { be used }\end{array}$ & $\begin{array}{l}\text { Pictures, definitions, exemplifications, technology aids, } \\
\text { attention to register, memory images, conversations and } \\
\text { dialogues, vocabulary tests, and recycling. }\end{array}$ \\
\hline Level two & $\begin{array}{l}\text { VTS and VDV that most (4-5) CATs believe } \\
\text { should be used }\end{array}$ & $\begin{array}{l}\text { Real objects, body actions, repetitions } \\
\text { guessing from context, word parts }\end{array}$ \\
\hline Level three & $\begin{array}{l}\text { VTS and VDV that a few (1-3) CATs believe } \\
\text { should be used }\end{array}$ & $\begin{array}{l}\text { Wall charts, scales, posters, translations } \\
\text { Labelling, semantic mapping, dictionary use, associations, } \\
\text { games }\end{array}$ \\
\hline Level four & $\begin{array}{l}\text { VTS and VDV that no CATs believe should } \\
\text { be used }\end{array}$ & Flash cards \\
\hline
\end{tabular}

The most frequent reasons teachers identified for choosing some VTS and VDV revealed some similarities and differences between both parties. Both types of teachers believe that strategies should be used provided that they are seen to be effective, preferred, and liked by their students. Less frequent reasons, in turn, revealed obvious differences between the ESPTs and CATs due to the nature of teaching language versus science. Therefore, integration between strategies was viewed as one reason for choosing some strategies by some ESPTs 
due to, for example, their knowledge of the teaching methodology which could allow them to proficiently switch between various strategies. The CATs, in turn, identified strategies that focus on meaning as one reason why they believe that this aspect of lexical information requires more specialized knowledge than form does.

\section{Teachers' Overall Beliefs on Who Should Teach ETV Items}

This study has generally found that both ESPTs and CATs believe that teaching ETV items that occur in both ESP and content areas is the job of both parties. According to them, each type of teacher is responsible for a particular aspect of the lexical information. All in all, the teachers believe that the linguistic aspects of ETV items which focus on the ETV items' form and involve grammar, pronunciation, and spelling, should be dealt with by ESPTs, while the content aspects which are more concerned with the meaning of the ETV items were viewed as the job of CATs.

Although the CATs believe that teaching ETV items is a joint job, they think that they are more responsible regarding this task. Therefore, the aspects of meaning and use of ETV items which normally require specialised subject knowledge, according to almost all the CATs interviewed, should be left to them when instructing these words. In a typical response, CAT AL expressed this overall belief about who should teach ETV items by saying: "The pure technical aspects of the technical words [should] of course [be taught] by the content teachers. But all the less technical aspects of the technical words may be introduced by the English teacher” (personal interview, May, 2009).

He gave an example from computing technology by saying:

An English teacher, for example, can teach the technical word "motherboard" which consists of two easy words_-"mother" and "board"-more easily than a word like "SDRAM" or "pebibyte" where it is difficult to guess what they actually mean. (personal interview, May, 2009)

The same position was reflected, for example, in ESP NL's answer:

When it comes to technical vocabulary I think they will be dealt with by both, yes. The ESPTs will deal with technical vocabulary from a linguistic point of view whereas the content teacher will deal with this from a content point of view. Let's say, he is after the piece of equipment; he is after the operation that he is explaining to his students. He is after the maintenance jobs that he is talking about. But, the teacher of English has nothing to do with the content vocabulary unless it has to be dealt with linguistically. (personal interview, May, 2009)

The participants expressed various common reasons for perceiving ETV items teaching as a joint job between both parties. They saw both sides as having some advantages over the other, but each side also lacking something. The first overall common reason for the belief about division of labour can be expressed as that ESPTs are more aware of teaching methods and strategies than CATs. Some ESPTs stated that an English language student in a university is trained in teaching methods, strategies and techniques. For example, ESP NS mentioned that: "When it comes to teaching strategies, the methodology of teaching vocabulary ESP teachers are more qualified. When it comes to knowledge, in the vocabulary itself, I think CAT teachers are more qualified because this is their job” (personal interview, May, 2009).

The main reason, according to the participants, is that ESPTs take certain courses on teaching methodologies, educational strategies and classroom management during their university studies. However, it has become common today in different parts of the world that both ESPTs and CATs take some methodology teaching courses 
in their areas of speciality as part of their university and departmental plan. The main difference, in the author's experience and from the discussions he had with some science students, is that most ESPTs have some lectures during their university studies about how to teach vocabulary, which is not a priority in a science major.

Another commonly held reason for the belief is that CATs are equipped with relevant subject matter knowledge. ESPTs believe that explanation of the specialised meaning part of the ETV item would be incompletely explained without the help of CATs. All ESPTs confirmed that they face certain challenges due to lacking the proper subject knowledge and that by having CATs take care of this part it makes teaching ETV items easier for them. Equally, all CATs believe that ESPTs lack sufficient knowledge to enable them to teach the more specialised ETV items in different content areas. To show how the issue of speciality matters when teaching ETV items, ESP PM said:

The content teacher knows what the technical word means, when the vocabulary is used and what it's used for and how often it's going to be used... I mean we don't have the technical knowledge, it's a very superficial knowledge except with some known technical words. (personal interview, May, 2009)

A final common belief held by the teachers is that ESPTs are equipped with linguistic knowledge. Because teaching ETV items involves teaching language and science, many participants believe that linguistic knowledge is important in this matter. Some CATs appreciate the role of the ESPTs in teaching the ETV form (e.g., the grammatical patterns of ETV items, pronunciation, spelling and word parts). In this regard, CAT VN stated: "In the financial management, the English language teacher can train and help the students on how to say the words right and also how to write them right” (personal interview, May, 2009).

This excerpt shows that CAT VN agrees that the lexical form (pronunciation and spelling) of business ETV items can be improved with the help of ESPTs.

\section{Conclusions}

It goes without saying that collaboration in teaching ETV items between language and subject teachers in any ESP context is a critical issue which provides a systematic road map for teaching these types of word effectively inside and outside the classroom. This study suggested some pedagogical implications to exploit the findings about collaboration between ESPTs and CATs at YIC from different angles. First of all, following Chung and Nation (2003), ESPTs are encouraged to deal with the linguistic aspects of the ETV items and to equip the students with the necessary VLS so that they can learn new technical vocabulary independently. Similarly, CATs are encouraged to take care of the subject-knowledge aspects of the same ETV items and to be involved directly in teaching them. Secondly, knowing what each party should do is, by itself, insufficient; therefore, team-teaching suggested by different researchers (e.g., Dudley-Evans \& St. John, 1998) seems to provide an ideal solution for the challenges each party faces since it familiarizes each party with his/her role and responsibilities. Thirdly, teachers in the target context seem to experience poverty of communication. Many participants revealed that no formal or informal gatherings take place between ESPTs and CATs; equally, rare informal chats seem to occur between the teachers from the same areas of expertise. Thus, exchanging ideas, improving teaching methodologies and detecting areas of strengths and weaknesses of the students, are just a few examples of the areas that will get affected by such ignorance. Teachers and officials within the college are 
highly encouraged to rethink the many benefits associated with sitting around the table to discuss different instructional issues of mutual interest. Finally, it is highly advised that CATs need to understand that they do a joint task with ESPTs in which each party integrates with, and completes, the other. Therefore, CATs are warned that failing to eliminate the authoritative attitude will gradually hinder the overall objectives of the collaborative teaching between them and their ESPT colleagues.

The future needed research about this under-researched area is enormous. However, it can be reliable idea to conduct a future study that scans all the overlapping ETV items between ESP and content area courses. Though this work requires long time and may be hindered by the frequent changes of the textbooks, it opens doors for establishing real cooperation, collaboration, and team work between both types of teacher. It will also help the practitioners to select shared vocabulary based in a real needs analysis which is central in any ESP context. One final recommendation is to conduct a study which investigates how positively or negatively the teachers' experience and students' level of performance in the content area influence the teachers' beliefs and practices in ESP classes.

\section{References}

Baumann, J., \& Kameénui, E. (2004). Vocabulary instruction: Research to practice. New York: The Guilford Press.

Boyd, F. A. (1991). Business Engüsh and the case method: A reassessment. TESOL Quarterly, 25(4), 729-734.

Byrd, P. (1979). EST in intensive English programs in the United States. TESOL Newsletter, 13(3), 15-18.

Chamberlain, R. (1980). The SP of the E. Team teaching in ESP. ELT Documents (106). London: The British Council.

Chung, T. M., \& Nation, I. S. P. (2003). Technical vocabulary in specialised texts. Reading in a Foreign Language, 15(2), 103-116.

Dudley-Evans, T., \& St. John, M. (1998). Developments in English for specific purposes. Cambridge: Cambridge University Press.

Duke, N., \& Pearson, P. (2002). Effective practices for developing reading comprehension. In J. Baumann, \& E. Kameénui (Eds.), Vocabulary instruction: Research to practice (pp. 89-99). New York: The Guilford Press.

Esteban, A., \& Martos, M. (2002). A case study of collaboration among the ESP practitioner, the content teacher, and the students. Revista Alicantina de Estudios Ingleses, 15, 7-21.

Fraser, S. (2005). The nature and role of specialized vocabulary: What do ESP teachers and learners need to know?. Retrieved from http://ir.lib.hiroshima-u.ac.jp/metadb/up/kiyo/AA11424332/h-gaikokugokenkyu9_63.pdf

Gardner, R., \& MacIntyre, P. A. (1992). Student's contribution to second language learning: Cognitive variables. Language Teaching, 25(2), 211-220.

Graves, M. (2009). Essential readings on vocabulary instruction. Newark, D.E.: International Reading Association.

Hiebert, E., \& Kamil, M. (2005). Teaching and learning vocabulary: Bringing research to practice. New Jersey: Lawrence Erlbaum Associates, Inc..

Hutchinson, T., \& Waters, A. (1987). English for specific purposes. Cambridge: Cambridge University Press.

Hyland, K. (2002). Specificity revisited: How far should we go now?. English for Specific Purposes, 21(4), 385-395.

Johnson, D. (1992). Approaches to research in second language learning. New York: Longman.

Jones, G. M. (1990). ESP textbooks: Do they really exist?. English for Speciflc Purposes, 9(1), 89-93.

Kennedy, C. (1980). Fundamental problems in ESP: Team teaching in ESP. ELT Documents, 106, 118-126.

Koh, M. (1988). The changing role of the ESL teacher and implications for ESP. In M. Ticko (Ed.), ESP: State of the art (pp. 74-79). Singapore: SEAMEO Regional English Language Center.

Koh, M. Y., \& Wong, I. (1990). A course in business communication for accountants. English for Speciflc Purposes, 9(3), $253-263$.

McKeown, M., \& Beck, I. (2004). Direct and rich vocabulary instruction. In J. Baumann, \& E. Kameénui (Eds.), Vocabulary instruction: Research to practice. New York: The Guilford Press.

McWilliam, N. (1998). What's in a word? Vocabulary development in multilingual classrooms. Stoke on Trent: Trentham Books.

Memory, D. M. (1990). Teaching technical vocabulary: Before, during, or after the reading assignment. Journal of Reading Behavior, 22(1), 39-53.

Mezynski, K. (1983). Issues concerning the acquisition of knowledge: Effects of vocabulary training on reading comprehension. Review of Educational Research, 53(2), 253-279. 
Nation, I. S. P. (1990). Teaching and learning vocabulary. Boston: Heinle \& Heinle Publishers.

Nation, I. S. P. (2001). Learning vocabulary in another language. Cambridge: Cambridge University Press.

Özturk, M. (2006). Vocabulary teaching. Dil Dergesi, 133, 20-28.

Rasekh, Z., \& Ranjbari, R. (2003). Metacognitive strategy training for vocabulary learning. TESL-EJ, 7(2), 5-15.

Rivers, W. M. (1983). Communicating naturally in a second language: Theory and practice in language teaching. Cambridge: Cambridge University Press.

Salager-Meyer, F. (1985). Specialist medical English lexis: Classificatory framework and rhetorical function: A statistical approach. EMP Newsletter, 2(2), 5-17.

Scott, J., \& Nagy, W. (2004). Developing word consciousness. In E. Hiebert, \& M. Kamil (Eds.), Teaching and learning vocabulary: Bringing research to practice. New York: Routledge.

Spack, R. (1988). Initiating ESL students into the academic discourse community: How far should we go?. TESOL Quarterly, 22(1), 29-51.

Stahl, S., \& Fairbank, M. (1986). The effects of vocabulary instruction: A model-based meta-analysis. Review of Educational Research, 56, 72-110.

Sutarsyah, C., Nation, I. S. P., \& Kennedy, G. (1994). How useful is EAP vocabulary for ESP? A corpus based study. RELC Journal, 25(2), 34-50.

Tabtabaei, O. (2007). Who qualifies to monitor an ESP course: A content teacher or a language teacher?. Indian Journal of Applied Linguistics, January-June, 77-85.

Weinsten, C. F., \& Mayer, R. F. (1986). The teaching of learning strategies. In M. C. Wittrock (Ed.), Handbook of research on teaching (pp. 315-327). New York: Macmillan Publishing Company.

Widdowson, H. (1978). Teaching language as communication. Oxford: Oxford University Press. 